\title{
Beneficial Effects of Fungicide Seed Treatments for Soybean Cultivars with Partial Resistance to Phytophthora sojae
}

\author{
A. E. Dorrance, Assistant Professor, and S. A. McClure, Research Assistant, Department of Plant Pathology, The \\ Ohio State University, OARDC, Wooster 44691-4096
}

\begin{abstract}
Dorrance, A. E., and McClure, S. A. 2001. Beneficial effects of fungicide seed treatments for soybean cultivars with partial resistance to Phytophthora sojae. Plant Dis. 85:1063-1068.

Phytophthora sojae is a yield-limiting soybean pathogen in areas where soils remain saturated for long periods of time. $P$. sojae has been successfully managed with single dominant resistance genes (Rps genes). The proportion of fields with populations of $P$. sojae capable of causing susceptible interactions with many of the Rps genes has increased in number. The fungicides metalaxyl and mefenoxam have been used both as in-furrow and seed treatments to provide protection against damping-off caused by $P$. sojae. To determine the plant age when partial resistance and Rps genes are effective against $P$. sojae, we evaluated a greenhouse assay in which soybean seeds were planted and inoculated with a zoospore suspension to compare the disease reaction of soybean seeds and seedlings. Efficacy of different fungicide rates also was evaluated using the cultivar with partial resistance with this inoculation technique. Seeds and seedlings of a cultivar with high levels of partial resistance were susceptible to infection by $P$. sojae while those of a cultivar with an Rps gene were resistant. For the cultivar with partial resistance, reductions in percent emergence and the number of damped-off seedlings were significantly higher for plants inoculated at the day of planting compared to inoculations of plants with unifoliates present (5 days after planting). Results also indicate that fungicide seed treatment on cultivars with partial resistance may be beneficial when the environmental conditions that favor $P$. sojae infections occur prior to soybean emergence. This greenhouse assay appears to be useful in examining overall fungicide efficacy; however, it did not detect consistent and quantifiable differences in rates of seed treatment fungicides.
\end{abstract}

Phytophthora sojae causes damping-off and root and stem rot of soybean in a number of production regions worldwide (22). Saturated soil conditions favor germination and development of oospores and sporangia and infection of soybean roots. The highest economic losses arise as a result of both direct plant loss and the costs of replanting when favorable environmental conditions occur just after planting (15). $P$. sojae has been managed successfully over the years with single gene resistance (Rps genes). There are 13 identified single genes for resistance, of which 8 are in allelic series $(4,15)$. The most commonly deployed Rps genes to date in commercial soybean cultivars have been Rps-1a, Rps$1 c, R p s-1 k, R p s-3 a, R p s-6$, and Rps-7. Fifty-five physiological races of $P$. sojae have been described to date $(1,10,23)$. As a result, in many production regions, popula-

Corresponding author: A. E. Dorrance

E-mail: dorrance.1@osu.edu

Salaries and research support were provided by state and federal funds appropriated to the Ohio Agricultural Research and Development Center, the Ohio State University.

Accepted for publication 7 June 2001 .

Publication no. D-2001-0726-01R

(C) 2001 The American Phytopathological Society tions of $P$. sojae now exist that have susceptible interactions with soybean cultivars that carry these Rps genes, rendering them ineffective $(1,10,17,23)$.

Disease management recommendations from many states increasingly emphasize the use of soybean cultivars with partial resistance (also called rate-reducing resistance, field resistance, or tolerance in the soybean industry; 2,9,11,15,20). Partial resistance in soybean cultivars restricts fungal colonization of plant tissue $(11,20)$ and is effective against all physiological races of the pathogen. Differences in yield among cultivars in $P$. sojae-infested soil have been attributed to the degree of partial resistance present in the cultivar $(19,21)$. Factors which govern partial resistance may or may not be effective at the seed or seedling stage. Schmitthenner (15) stated that "after germination many soybean cultivars quickly develop partial resistance, however, and may not be damaged after the seedling stage". As the number of fields with populations of $P$. sojae capable of causing disease on soybean cultivars with Rps genes increases, producers will be forced to rely on cultivars with high levels of partial resistance unless new Rps genes are identified. Additional disease management strategies are necessary to ensure minimal yield losses occur when conditions are favorable for severe disease development.
Metalaxyl applied as an in-furrow or seed treatment has reduced plant emergence loss and increased yields of susceptible soybean cultivars when $P$. sojae was present and the environment was conducive to infection $(2,7)$. However, the seed treatments had no effect on yields of partially resistant (tolerant) soybean cultivars in these same studies $(2,7)$. Soybean seed treatment with metalaxyl has significantly increased yields in conservation tillage production systems (6). Despite the beneficial effects of seed treatment on susceptible soybean cultivars, a low percentage of soybean seed planted is treated with metalaxyl or mefenoxam in Ohio and other areas where $P$. sojae is endemic. In addition, recommended labeled rates of fungicide to adequately manage $P$. sojae range from 15.5 to $31.0 \mathrm{~g}$ a.i. of metalaxyl per $100 \mathrm{~kg}$ of seed $(0.75$ to $1.5 \mathrm{fl}$ oz/hundred weight) and 7.5 to $15.0 \mathrm{~g}$ a.i. of mefenoxam per $100 \mathrm{~kg}$ of seed $(0.32$ to $0.64 \mathrm{fl} \mathrm{oz} /$ hundredweight).

Testing for efficacy of fungicide seed treatments in the field has been challenging due to uneven inoculum distribution and dependence on natural environment conditions for development of disease. A greenhouse technique which reliably evaluates the efficacy of seed treatment fungicides that could also differentiate specific rates against $P$. sojae could be useful to pathologists who make recommendations to producers as well as agrochemical companies.

Our objectives in this study were: to determine when partial resistance to $P$. sojae in soybean seeds and seedlings provides some protection compared to single Rps gene using greenhouse inoculations, and to determine if a greenhouse inoculation assay could adequately assess the efficacy of a specific fungicide as well as fungicide rates.

\section{MATERIALS AND METHODS}

Inoculum production. Zoospores of $P$. sojae (race 7, virulence pathotype 1a, 3a, 4 , 5,6 , and 7) were used as inoculum in all greenhouse experiments. Zoospores were produced by salt washing of 2-day-old cultures grown on dilute lima bean extract in 25-ml Erlenmeyer flasks (17). Extracts were decanted and replaced with $25 \mathrm{ml}$ of Chen-Zentmeyer salt solution $(\mathrm{pH}$ 7.0) every $15 \mathrm{~min}$ for $1 \mathrm{~h}$. After the final salt wash, $25 \mathrm{ml}$ of sterile distilled water was added to flasks, which were then incubated 
in the light overnight. After 16 to $18 \mathrm{~h}$, zoospores were collected, counted with a hemocytometer, and diluted to approximately $1 \times 10^{4}$ zoospores $/ \mathrm{ml}$. Later experiments required a greater quantity of zoospores. Zoospores were produced for these experiments by washing 3- to 5-day-old colonies produced on V8 juice agar plates (approximately 40 to 45 plates) similar to the method reported by Ho and Hickman (8).

Greenhouse inoculations. For each greenhouse experiment, 10 soybean seeds were planted in coarse vermiculite (ThermO-Rock East, New Eagle, PA) in 6.4-cm plastic pots in the greenhouse. Plants were inoculated with a zoospore suspension by placing pots in 470-ml styrofoam cups containing $200 \mathrm{ml}$ of zoospore $\left(1 \times 10^{4}\right)$ suspension for $24 \mathrm{~h}$. Pots were then removed from inoculum and placed on a greenhouse bench in a randomized complete block design of one pot each for each treatment in each experiment, with three replications for plant age evaluations and four replications for seed treatment evaluations. A water control was included in each experiment for each treatment to ensure adequate germination and plant health in this study, but this data was not included in the final statistical analysis. The pots were watered as needed to maintain high moisture levels.

Plant age evaluations. Two soybean cultivars were used in these experiments: Conrad, which has no Rps genes and high levels of partial resistance; and Resnik, which has Rps-1k and moderate levels of partial resistance to $P$. sojae. To obtain seedlings of different ages for inoculation, pots were planted in a sequence of $0,2,3$,
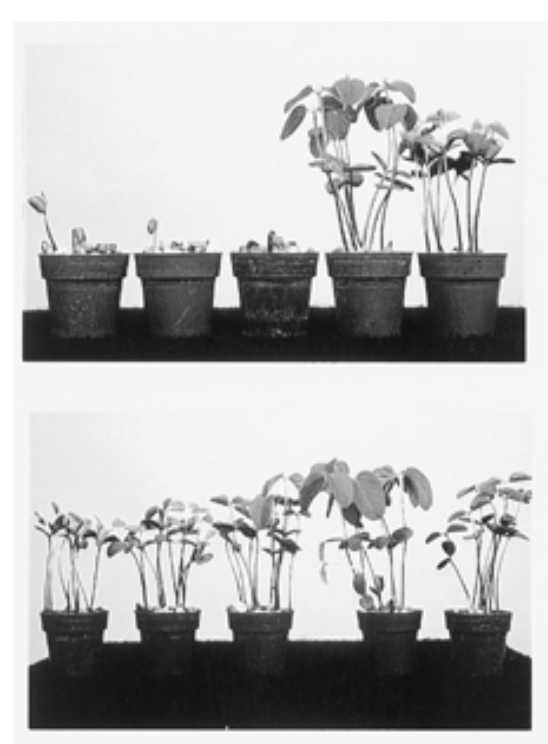

Fig. 1. Inoculation of two soybean cultivars with zoospores of Phytophthora sojae. Top, soybean cultivar Conrad with partial resistance; bottom, Resnik with Rps-1k resistance. The pots in the picture are (left to right) inoculations at $0,2,3$, and 5 days after planting and a 3-day-old uninoculated control.
4, 5, 6, 7, 10, and 14 days. The $P$. sojae isolate (R7) chosen for these studies causes a resistant reaction when used to inoculate soybean plants with Rps-1k. Pots with plants of the soybean cv. Resnik or Conrad of the different ages were then inoculated on the same day. The number of seedlings with symptoms of Phytophthora dampingoff, percent plant emergence, and plant height was recorded after 7 days. Percent
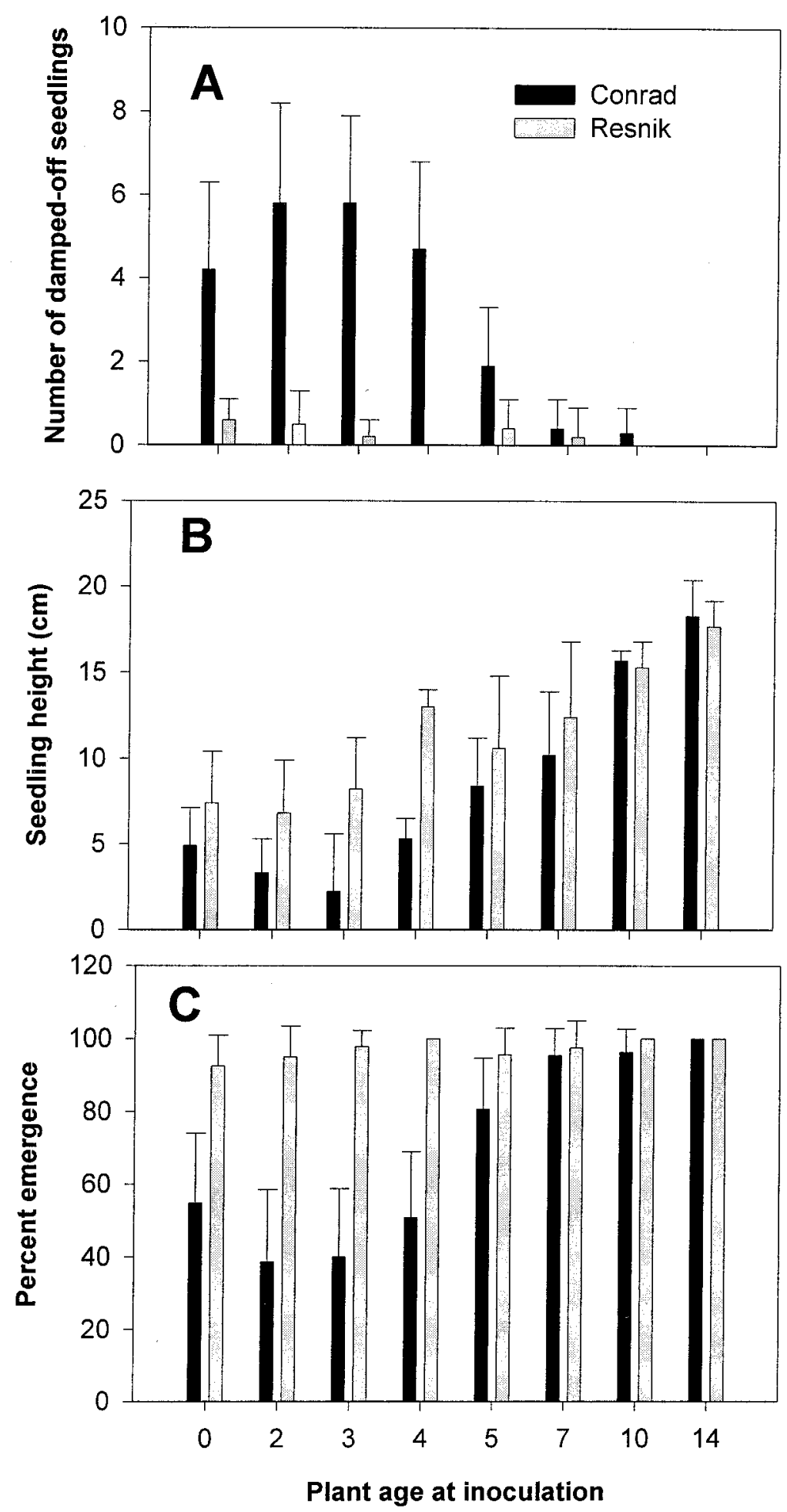

Fig. 2. A, Number of plants with pre- and postemergence damping off, B, seedling height, and $\mathbf{C}$, percent emergence of two soybean cultivars, Conrad (partial resistance) and Resnik (Rps-1k), following inoculation of 0-, 2-, 3-, 4-, 5-, 7, 10-, and 14-day-old plants with Phytophthora sojae race 7 (vir 1a, 3a, 7) which is incompatible with Rps-1k to determine when resistance is effective. Fisher's protected least significant difference (LSD) values $(P \leq 0.05)$ are 2.1, 1.9, and 17.9 for Conrad; and not significant, 0.9 , and not significant for Resnik for number of damped off seedlings, seedling height, and percent stand, respectively. The variety by age $\operatorname{LSD}(P<0.025)$ is $1.05,1.05$, and 9.7 for number of damped off seedlings, seedling height, and percent stand, respectively. 
plant emergence refers to the percentage of the number of seeds planted that developed into standing plants without symptoms of damping-off. This study was repeated three times; inoculations took place on 1 February, 23 February, and 29 March 1999.

Seed treatment evaluations. Two fungicides, metalaxyl (Allegiance, Gustafson LLC, Plano TX) and mefenoxam (Apron XL, Novartis Crop Protection, Greensboro, NC), were used at the most commonly applied (Ray Knake, Gustafson LLC, personal communication) as well as recommended rates for Pythium spp. (metalaxyl and mefenoxam at 4.1 and 3.75 $\mathrm{g}$ a.i. per $100 \mathrm{~kg}$ of seed, respectively) and Phytophthora spp. (metalaxyl at 15.5 and $31.0 \mathrm{~g}$ a.i. and mefenoxam at 7.5 and 15.0 $\mathrm{g}$ a.i. per $100 \mathrm{~kg}$ of seed). Seed (454 g) of the soybean cv. Conrad was treated at each fungicide rate, then used for each experiment. Fungicide was added to water for a final volume of $2.37 \mathrm{ml}$, mixed thoroughly, and added to the seed in plastic bags. To ensure thorough coverage, seed was shaken and mixed for $15 \mathrm{~min}$ until there was no fungicide residue visible on the inside of the bags. Bags were then left open in a forced air hood at room temperature to allow seed treatment to dry. The seed was stored in a cool, dry place until planted. Plant ages evaluated in this study included $1,3,5$, and 7 days. Seed treatments in this study included untreated, three rates of metalaxyl, three rates of mefenoxam inoculated with $P$. sojae zoospores, and an untreated, uninoculated control. The number of Phytophthora damped-off seedlings, plant emergence, plant height, and whole plant and root fresh weight were recorded after 7 days. Inoculations for this study were on 8 and 28 September 1999.

Statistical analysis. The arcsine square root transformation of the percent emergence was used for statistical analysis. For each study, the experiments were combined and the transformed percent emergence, plant heights, root and top fresh weights, and the number of plants with root rot for each treatment were analyzed by an analysis of variance with the Proc GLM procedure (SAS, Cary, NC). The experiments were then analyzed separately for the seed treatment-plant age study. Fisher's protected least significant difference (LSD) was used to separate the means

Table 1. Combined analysis of variance for three greenhouse experiments in which the soybean cultivars Resnik (specific gene resistance, Rps-1k) and Conrad (partial resistance, rps) were inoculated with Phytophthora sojae (race 7, vir 1a, 3a, 5, 6, and 7) at 0, 2, 3, 4, 5, 7, 10, and 14 days after planting to determine at what plant age resistance is effective ${ }^{a}$

\begin{tabular}{lcccc}
\hline Source & df & $\begin{array}{c}\text { Damped-off } \\
\text { seedlings }(\boldsymbol{F})\end{array}$ & Plant height $(\boldsymbol{F})$ & $\begin{array}{c}\text { Percent } \\
\text { emergence }(\boldsymbol{F})\end{array}$ \\
\hline Experiment & 2 & $6.08^{*}$ & $240.01^{* *}$ & $6.73^{*}$ \\
Rep (Experiment) & 6 & $\ldots$ & $\ldots$ & $\ldots$ \\
Cultivar & 1 & $124.13^{* *}$ & $141.01^{* *}$ & $170.81^{* *}$ \\
Experiment $\times$ cultivar & 2 & 1.48 & $29.14^{* *}$ & 0.10 \\
Age & 7 & $12.96^{* *}$ & $84.41^{* *}$ & $17.84^{* *}$ \\
Experiment $\times$ age & 7 & 1.35 & $5.07^{* *}$ & 2.02 \\
Cultivar $\times$ age & 7 & $11.30^{* *}$ & $6.42^{* *}$ & $11.79^{* *}$ \\
Experiment $\times$ cultivar $\times$ age & 7 & 1.23 & 0.81 & 1.44 \\
Error & 62 & $\ldots$ & $\ldots$ & $\ldots$ \\
\hline
\end{tabular}

${ }^{a} F=F$ value, $*$ and $* *$ indicate significance at $P \leq 0.05$ and $P \leq 0.01$, respectively. Percent emergence $=\arcsin ($ sqrt emergence) adjusted to 1.
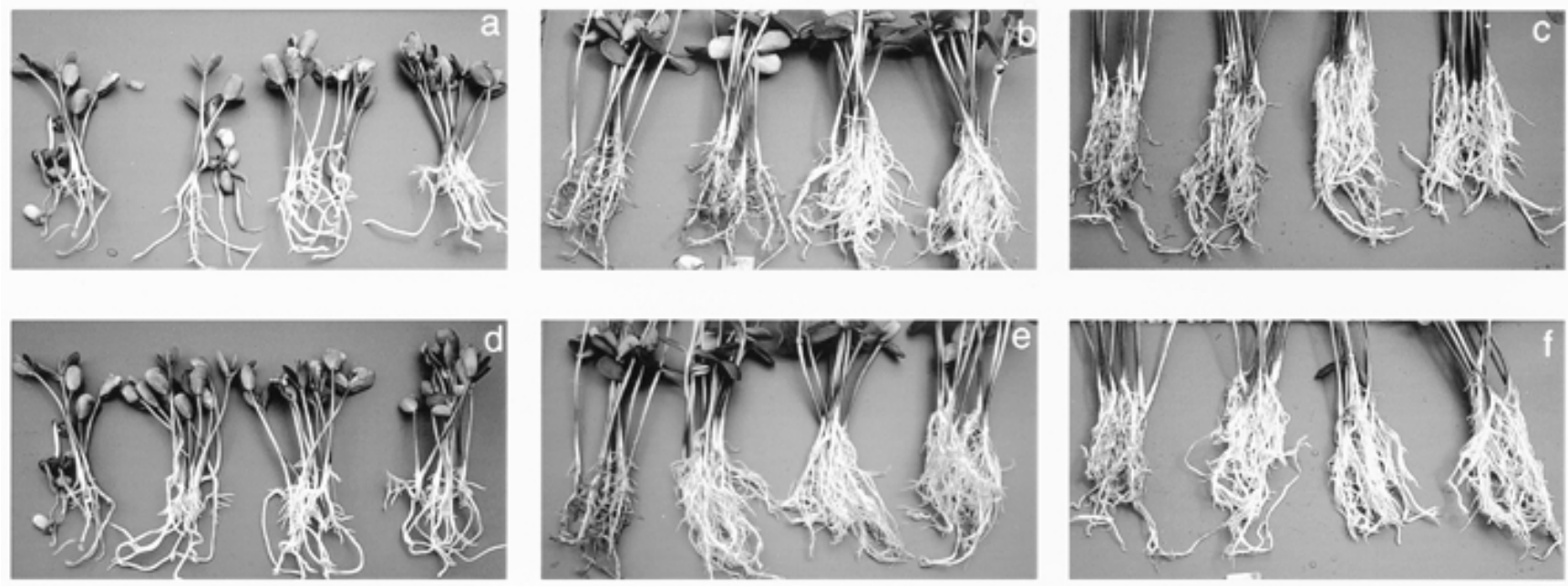

Fig. 3. Soybean seedlings of the cultivar Conrad with partial resistance, following inoculation with zoospores of Phytophthora sojae at a and d, $1, \mathbf{b}$ and $\mathbf{e}$, 5 , and $\mathbf{c}$ and $\mathbf{f}, 7$ days after planting with $\mathbf{a}, \mathbf{b}, \mathbf{c}$, metalaxyl at $0,4.1,15.5$, and $31.0 \mathrm{~g}$ a.i. per $100 \mathrm{~kg}$ of seed and $\mathbf{d}, \mathbf{e}, \mathbf{f}$, mefenoxam at $0,3.75,7.5$, and $15.0 \mathrm{~g}$ a.i. per $100 \mathrm{~kg}$ of seed. 
The effect of seedling age at inoculation was significantly different for all parameters for the soybean cv. Conrad with partial resistance (Fig. 2). Only seedling height was significantly different among the Resnik treatments, which would be expected when early and late seedling ages are compared. The most striking differences on the effects of inoculation at early plant ages for these two cultivars was the final percent emergence (Fig. 2C). Final percent emergence for soybean cv. Conrad ranged from 38 to $55 \%$ emergence, compared with Resnik at 93 to $100 \%$ emergence when seedlings were inoculated at 0 to 4 days after planting. There was significantly less seedling emergence for the cv. Conrad when plants were inoculated at seed, 2, 3, 4, or 5 days compared with inoculations at 7, 10, and 14 days ( $\mathrm{LSD}=13.9, P \leq 0.05)$.

Seed treatment and plant age. Phytophthora root rot developed on seedlings of all plant ages and at all fungicide rates, with the exception of the highest rates of both fungicides (Fig. 3) and the uninoculated, untreated control (not shown). The greenhouse experiments were highly significantly different from each other for final percent emergence, plant height, and root weight. The main effect of fungicide seed treatment was significant $(P<0.001)$ for final percent emergence, root weight $(P$ $=0.012)$, plant height $(P<0.05)$, and plant weight $(P<0.05)$. Seedling age at inoculation was only significantly different for plant height $(P=0.003$; Table 2$)$. There were highly significant interactions $(P<$ 0.01 ) between the experiments and plant age for root weight, plant height, percent germination, and the number of plants with root rot, as well as between experiment by treatments for plant height, top weight, and root weight. The trends from the two experiments were similar; however, due to the significant interactions, the results from one of the greenhouse experiments is presented (Fig. 4). All fungicide seed treatments and the uninoculated, untreated control were significantly different $(P<$ 0.05 ) from the inoculated non-fungicide- treated control in pairwise comparisons using Fisher's protected LSD for final percent emergence, fresh plant weight, and root weight. Consistent significant differences between the fungicide seed treatments did not occur. The one exception was for the fungicide seed treatment with metalaxyl at $4.1 \mathrm{~g}$ a.i. per $100 \mathrm{~kg}$ of seed, which was significantly different from the other treatments for root weight and plant weight. Interestingly, the mefenoxam at 7.5 $\mathrm{g}$ a.i. per $100 \mathrm{~kg}$ of seed was significantly different than the mefenoxam at $15 \mathrm{~g}$ a.i. per $100 \mathrm{~kg}$ of seed for plant height, but not different than the lower rate of mefenoxam at $3.75 \mathrm{~g}$ a.i. per $100 \mathrm{~kg}$ of seed in pairwise comparisons (Fig. 4).

\section{DISCUSSION}

Seed or in-furrow treatments with metalaxyl have been recommended for management of $P$. sojae in fields where Phytophthora root rot is chronic $(7,15,16)$. Several studies have shown no benefit of seed treatment with metalaxyl for some cultivars $(2,6,7)$. This could be partially explained by our first series of experiments, in which no disease developed on seed or seedlings of a resistant soybean cultivar with an Rps gene. However, the soybean cv. Conrad, with a high level of partial resistance, was highly susceptible to infection by $P$. sojae from the day of planting until 5 days after planting. The effect of plant age on susceptibility to Phytophthora spp. has been documented previously in other host systems. Young potato plants, 4 to 6 weeks after planting, are more susceptible to $P$. infestans $(5,18)$. Tomatoes developed larger lesions when inoculated with $P$. capsici at 6 to 8 weeks after transplanting, compared with inoculations at 10 and 12 weeks after transplanting (14). Jimenez and Lockwood (9) indicated that the maximum effects of disease are expressed when younger seedlings, 2 to 32 days old, of a susceptible soybean cultivar were inoculated with a $P$. sojae zoospore suspension. The differences between inoculated and uninoculated soybean plants, 16 days of age and older, were not significantly different at the time the measurements were taken in this study.

Ontogenetically determined resistance (also known as adult plant resistance) is a type of quantitatively inherited resistance that develops during plant maturation (3). For example, adult plant resistance to rust (Uromyces appendiculatus) in common bean is expressed as lower disease intensity on the upper plant leaves compared with primary leaves (12). Our studies indicate that the lack of ontogenic resistance expression in seeds and seedlings of soybean cultivars with partial resistance makes them highly susceptible to infection by $P$. sojae. Whether the delay in expression of resistance to $P$. sojae is due to changes in root structure, root age, biochemical changes, or other genetically determined factors has yet to be determined. Once genetic components of partial resistance are identified in soybeans, these types of questions can be answered.

Our data clearly demonstrate the potential benefits of fungicide seed treatment with higher plant emergence, plant height, fresh whole plant weight, and root weight for soybean cultivars with partial resistance to $P$. sojae. This greenhouse assay could be used to evaluate the efficacy of new fungicide materials for $P$. sojae. However, our technique did not consistently separate the effects of fungicide rates, which may be due to a number of reasons. The medium in these pots is coarse vermiculite, which allows for ease of movement of $P$. sojae zoospores. Pfender et al. (13) demonstrated that zoospores moved only 65 and $24 \mathrm{~mm}$ in a sandy-loam soil and silt-loam soil, respectively. Soybeans produced in Ohio are planted in diverse soil types; many have $60 \%$ clay and are prone to water retention. These heavy soils may have other properties which, combined with heavy spring rains, may warrant the use of higher rates of seed treatment materials than are currently recommended. Metalaxyl applied infurrow has been shown in field studies (16) to provide longer protection against Phytophthora root rot than when metalaxyl

Table 2. Analysis of variance for percent plant stand, plant height, whole plant weight, and root fresh weight following fungicide seed treatment with metalaxyl (Allegiance) at 4.14, 15.51, and $31.01 \mathrm{~g}$ a.i. per $100 \mathrm{~kg}$ of seed; mefenoxam (Apron XL) at 3.75, 7.5, and $15.0 \mathrm{~g}$ a.i. per $100 \mathrm{~kg}$ of seed; and untreated seed for the soybean cultivar Conrad after inoculation of seedlings with a Phytophthora sojae zoospore suspension at $0,3,5$, and 7 days in a greenhouse study ${ }^{\mathrm{a}}$

\begin{tabular}{|c|c|c|c|c|c|c|c|c|c|c|c|c|c|}
\hline \multirow[b]{2}{*}{ Source $^{b}$} & \multirow[b]{2}{*}{ df } & \multicolumn{3}{|c|}{ Percent emergence } & \multicolumn{3}{|c|}{ Plant height } & \multicolumn{3}{|c|}{ Plant fresh weight } & \multicolumn{3}{|c|}{ Root fresh weight } \\
\hline & & MS & $\mathbf{F}$ & $\mathbf{P}$ & MS & $\mathbf{F}$ & $\mathbf{P}$ & MS & $\mathbf{F}$ & $\mathbf{P}$ & MS & $\mathbf{F}$ & $\mathbf{P}$ \\
\hline E & 1 & 711.47 & 12.01 & 0.013 & 76.37 & 33.47 & 0.001 & 26.428 & 3.20 & 0.124 & 96.862 & 152.53 & $<0.001$ \\
\hline$R(E)$ & 6 & 59.23 & & & 2.28 & & & 8.270 & & & 0.635 & & \\
\hline $\mathrm{T}$ & 7 & 879.76 & 10.13 & $<0.001$ & 29.00 & 4.29 & 0.048 & 78.315 & 6.31 & 0.020 & 18.322 & 7.73 & 0.012 \\
\hline $\mathrm{T} \times \mathrm{E}$ & 6 & 50.99 & 0.59 & 0.740 & 6.76 & & & 12.411 & & & 2.369 & & \\
\hline Age & 3 & $1,094.29$ & 4.80 & 0.115 & $1,823.39$ & 72.06 & 0.003 & 386.751 & 5.88 & 0.089 & 35.779 & 1.74 & 0.330 \\
\hline $\mathrm{E} \times \mathrm{A}$ & 3 & 227.97 & $\ldots$ & $\ldots$ & 25.30 & $\ldots$ & $\ldots$ & 65.754 & & $\ldots$ & 20.563 & $\ldots$ & $\ldots$ \\
\hline $\mathrm{T} \times \mathrm{A}$ & 21 & 276.51 & 3.18 & $<0.001$ & 5.10 & 1.48 & 0.201 & 12.180 & 2.90 & $<0.001$ & 2.440 & 1.37 & 0.249 \\
\hline $\mathrm{T} \times \mathrm{E} \times \mathrm{A}$ & 18 & 96.09 & 1.11 & 0.349 & 3.44 & $\ldots$ & $\ldots$ & 6.099 & 1.45 & 0.114 & 1.775 & $\ldots$ & $\ldots$ \\
\hline Error & 174 & 86.82 & $\ldots$ & $\ldots$ & 1.88 & $\ldots$ & $\ldots$ & 4.204 & $\ldots$ & $\ldots$ & 0.846 & $\ldots$ & $\ldots$ \\
\hline
\end{tabular}

\footnotetext{
a Percent emergence $=$ percentage of the number of seeds that developed into plants without symptoms of $P$. sojae damping-off; MS = mean squares.
}

${ }^{\mathrm{b}} \mathrm{E}=$ experiment, $\mathrm{R}=$ rep, $\mathrm{T}=$ treatments, $\mathrm{A}=$ seedling age of $0,3,5$, and 7 days after planting for inoculations. 
is applied as a seed treatment. In order to adequately evaluate rates of material in a greenhouse, screening technique inoculations of more susceptible soybean cultivars at later growth stages may be necessary.

Our studies suggest that seeds and seedlings with high levels of partial resistance are still vulnerable to attack by $P$. sojae during seed germination until unifoliates are visible. Soybean cultivars with partial resistance that are planted in fields where environmental conditions conducive to
Phytophthora root rot development are likely to exist could benefit from a fungicide seed treatment.

\section{ACKNOWLEDGMENTS}

We thank P. Lipps and M. Ellis for critically reviewing this manuscript, and B. Bishop for assistance with the statistical analysis.

\section{LITERATURE CITED}

1. Abney, T. S., Melgar, J. C., Richards, T. L., Scott, D. H., Grogan, J., and Young, J. 1997. New races of Phytophthora sojae with Rps1-d virulence. Plant Dis. 81:653-655.
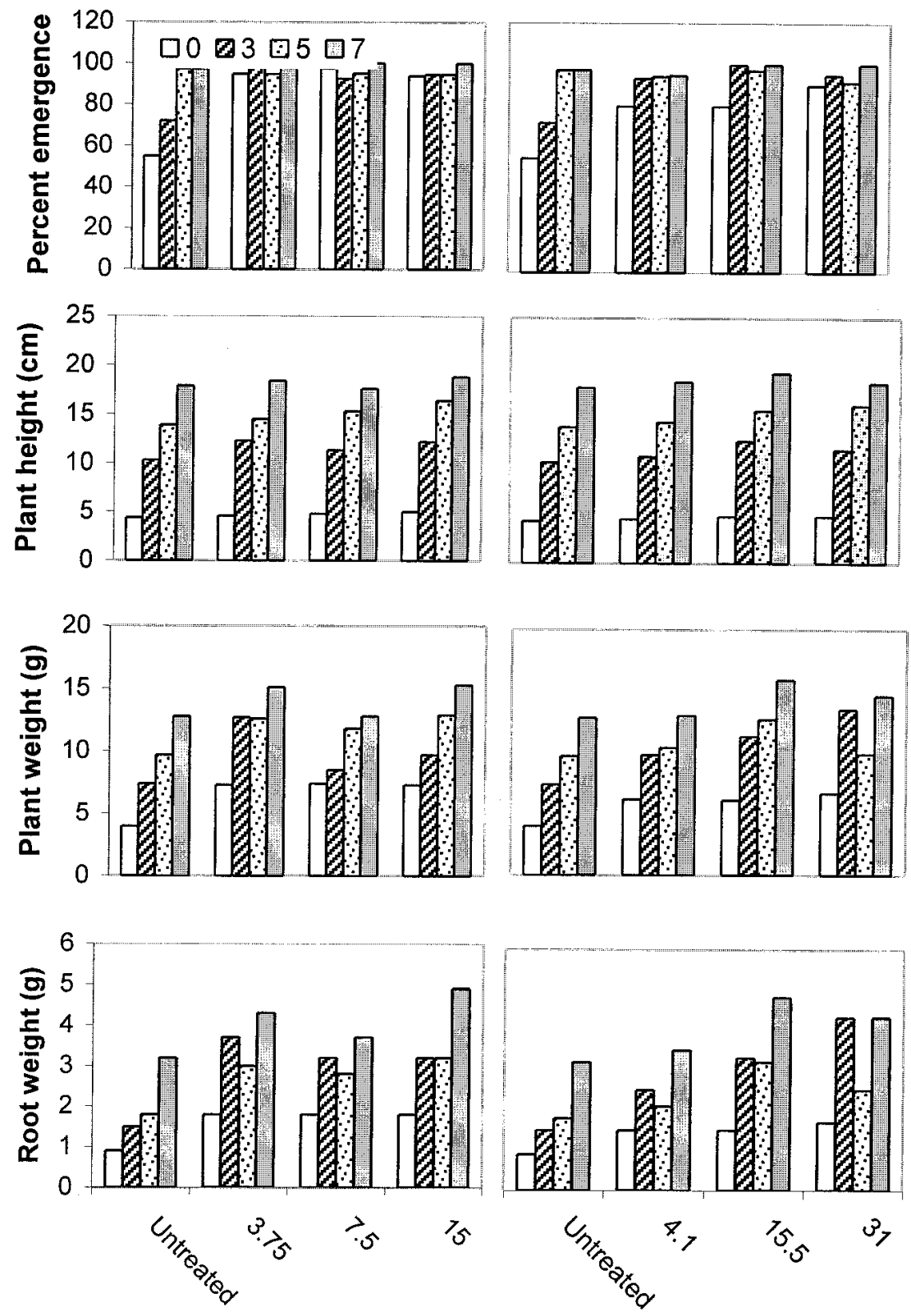

Mefenoxam (g a.i./100kg)

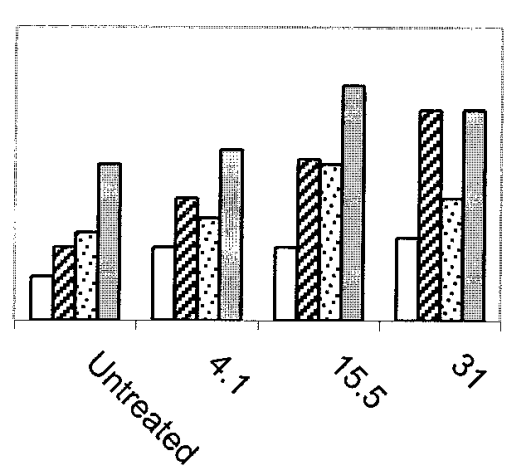

Metalaxyl (g a.i. $/ 100 \mathrm{~kg})$

Fig. 4. Percent emergence, average plant height, and fresh weight of plants and roots of soybean seedlings of partially resistant $\mathrm{cv}$. Conrad, inoculated at $0,3,5$, and 7 days from one of two greenhouse experiments. Soybean seed was untreated or treated with mefenoxam at $3.75,7.5$, and $15.0 \mathrm{~g}$ a.i. per $100 \mathrm{~kg}$ of seed or metalaxyl at $4.1,15.5$, and $31.0 \mathrm{~g}$ a.i. per $100 \mathrm{~kg}$ of seed. Fisher's protected least significant difference (LSD) values $(P \leq 0.05)$ among the seed treatments are $8.2,0.7,1.4$, and 0.4 for percent germination, plant height, whole plant weight, and root fresh weight, respectively. Fisher's protected LSD values $(P \leq 0.05)$ for comparisons of plant ages are $6.2,0.6,1.0$, and 0.3 for percent emergence, plant height, whole plant weight, and root fresh weight, respectively.
2. Anderson, T. R., and Buzzell, R. I. 1982. Efficacy of metalaxyl in controlling Phytophthora root and stalk rot of soybean cultivars differing in field tolerance. Plant Dis. 66:1144-1145.

3. Boyle, C., and Aust, H. J. 1997. Pages $254-$ 271 in: Resistance of Crop Plants Against Fungi. H. Hartleb, R. Heitefuss, and H. H. Hoppe, eds. Gustave Fisher Verlag, Jena, Germany.

4. Diers, B. W., Mansur, L., Imsande, J., and Shoemaker, R. C. 1992. Mapping Phytophthora resistance loci in soybean with restriction fragment length polymorphism markers. Crop Sci. 32:377-383.

5. Dorrance, A. E., and Inglis, D. A. 1997. Assessment of greenhouse and laboratory screening methods for evaluating potato foliage for resistance to late blight. Plant Dis. 81:1206-1213.

6. Guy, S. O., and Oplinger, E. S. 1989. Soybean cultivar performance as influenced by tillage system and seed treatment. J. Prod. Agric. 2:57-62.

7. Guy, S. O., Oplinger, E. S., and Grau, C. R. 1989. Soybean cultivar response to metalaxyl applied in furrow and as a seed treatment. Agron. J. 81:529-532.

8. Ho, H. H., and Hickman, C. J. 1967. Asexual reproduction and behavior of zoospores of Phytophthora megasperma var. sojae. Can. J. Bot. 45:1963-1981.

9. Jimenez, B., and Lockwood, J. L. 1980. Laboratory method for assessing field tolerance of soybean seedlings to Phytophthora megasperma var. sojae. Plant Dis. 64:775778.

10. Leitz, R. A., Hartman, G. L., Pedersen, W. L., and Nickell, C. D. 2000. Races of Phytophthora sojae on soybean in Illinois. Plant Dis. 84:487.

11. McBlain, B. A., Zimmerly, M. M., Schmitthenner, A. F., and Hacker, J. K. 1991 Tolerance to Phytophthora rot in soybean: I. Studies of the cross 'Ripley' $\times$ 'Harper'. Crop Sci. 31:1405-1411.

12. Mmbaga, M. T., and Steadman, J. R. 1992. Adult plant rust resistance associated with leaf pubescence in common bean. Plant Dis. 76:1230-1236.

13. Pfender, W. F., Hine, R. B., and Stanghellini, M. E. 1977. Production of sporangia and release of zoospores by Phytophthora megasperma in soil. Phytopathology 67:657663.

14. Roberts, P. D., Urs, R. R., and McGovern, R. J. 2000. Age and varietal response of tomato to infections by Phytophthora capsici. (Abstr.) Phytopathology 90:S65.

15. Schmitthenner, A. F. 1985. Problems and progress in control of Phytophthora root rot of soybean. Plant Dis. 69:362-368.

16. Schmitthenner, A. F. 1988. Phytophthora rot of soybean. Pages 71-80 in: Soybean Diseases of the North Central Region. T. D. Wyllie and D. H. Scott, eds. American Phytopathological Society Press, St. Paul, MN.

17. Schmitthenner, A. F., and Bhat, R. G. 1994. Useful Methods for Studying Phytophthora in the Laboratory. OARDC Spec. Circ. 143.

18. Stewart, H. E. 1990. Effect of plant age and inoculum concentration on expression of major gene resistance to Phytophthora infestans in detached potato leaflets. Mycol. Res. 94:823-826.

19. St. Martin, S. K., Scott, D. R., Schmitthenner, A. F., and McBlain, B. A. 1991. Relationship between tolerance to Phytophthora rot and soybean yield. Plant Breed. 113:331-334.

20. Tooley, P. W., and Grau, C. R. 1984. Field characterization of rate-reducing resistance to Phytophthora megasperma f. sp. glycinea in soybean. Phytopathology 74:1201-1208. 
21. Tooley, P. W., and Grau, C. R. 1984. The relationship between rate-reducing resistance to Phytophthora megasperma f. sp. glycinea and yield of soybean. Phytopathology 74:1209. 1216.
22. Wrather, J. A., Anderson, T. R., Arsyad, D. M., Gai, J., Ploper, L. D., Porta-Puglia, A., Ram, H. H., and Yorinori, J. T. 1997. Soybean disease loss estimates for the top 10 soybean producing countries in 1994. Plant Dis.
81:107-110.

23. Yang, X. B., Ruff, R. L., Meng, X. Q., and Workneh, F. 1996. Races of Phytophthora sojae in Iowa soybean fields. Plant Dis. 80:1418-1420. 